\title{
It is Imperative to Innovate the Phenomenon of Valuing Scientific Research above Teaching Work in Teaching and Research University of China
}

\author{
Haibo ZHAO \\ Electrical Engineering College of Tongling University, Tongling Anhui, China, 244000 \\ happyzhaohaibo@126.com
}

\begin{abstract}
Aiming at the abnormal phenomenon of valuing scientific research above teaching work in teaching and research university in China, the main causes of the abnormal phenomenon were analyzed from income return aspect in this paper by surveying some universities. This paper penetrated the abnormal phenomenon of scientific research in university from five aspects as followed: too much scientific research funds disbursed, academic corruption, the practical value of scientific research achievements, teacher applying project, manuscript accepted by university journal, has an insight into the abnoamal phenomenon of teaching work in university from four aspects as followed: teacher's teaching attitude, teacher's professional level, teacher's mandarin level, applying teaching achievement award. These abnormal phenomena result in teacher benefiting most and student hurted most in the end. Practical measurements to prevent abnormal phenomenon were proposed, in order to cause general education workers to attach a great deal of value to the imbalance phenomenon of scientific research and teaching work in teaching and research university in today's China, making sure the universities can develop healthy and sustainable.
\end{abstract}

Index Terms - university; scientific research; teaching; innovation

\section{Introduction}

Teaching and research university is a very important university model in Chinese education system, taking on the task of scientific research and teaching work, undergraduate education and postgraduate education. But at present, the imbalance phenomenon of scientific research and teaching work in Chinese teaching and reaearch university still exist. The general secretary of the $\mathrm{CPC}$ (the Central Committee of the Communist of China) Central Committee, President, chairman of the Central Military, the central comprehensive reform group leader Xi Jinping presided over the first meeting of comprehensively deepen reform leading group and made an important speech in the afternoon of January 22,2014. He emphasized that comprehensively deepen the reformation, we have favorable conditions, have the basis of practice, have the theoretical preparation, also have a good atmosphere, we must grasp the overall situation, size up the situation, overall planning, scientific implementation, fully arouse the enthusiasm of all aspects, and unswervingly toward comprehensively deepen reform goals. Therefore, it is necessary that I respond to the party's call "from CPC to local comprehensively deepen reform thoughts", in line with the attitude of seeking truth from facts, study the innovation of the imbalance phenomenon of scientific research and teaching work in teaching and research university of China, and put forward practical measures to solve the imbalance phenomenon. Many domestic scholars have studied the imbalance phenomenon of Chinese teaching and research university ${ }^{[1-11]}$, representative works such as Xu Jun analyzed the reasons of scientific research and teaching work imbalance in detail and proposed many coordinated countermeasures ${ }^{[12]}$. I will not repeat here. The above literature did not reveal unknown sides behind the imbalance, and most of the proposed strategies are not practical or would be difficult to implement in practice. I uncover the "ugly" mask in scientific research and teacing work and propose some practical strategies to solve the imbalance by surveies of some universities and several interviews with teachers.

Confined by various conditions, I chose two provinces, a total of 10 universities and 1500 questionnaires, each province issued 750 copies, each university 150 questionnaires, a total recovery of 1369 , including 1274 valid questionnaires, and interviews with many teachers.

\section{Results of questionnaires}

The inquiry result showed that $90.8 \%$ of teachers chose to be interested in doing scientific research, the rest of teachers chose not to be interseted in doing scientific research or indifferent. It shows that most of university teachers are interested in doing scientific research, only $8.2 \%$ of teachers chose to be interested in teaching work, most of teachers chose not to be interested in teaching work. The phenomenon of valuing scientific research above teaching work is abnormal.

3. Analysis on main reasons of most of teachers choose to be interested in doing scientific research, not to be interested in teaching work

The university scientific research is that teachers publish papers, monographs, patent, taking charge of project and teacher's paper awarded etc. I interviewed several teachers, all said that university professional evaluation mainly rely on published articles and hosting projects, scientific research needed to be done, otherwise my title is a teaching assistant or lecturer in a lifetime. In addition, almost all universities have 
scientific research reward, teachers published papers or patents or paper awarded, schools have a reward. Some university scientific research reward is very high, this will entice teachers to do research, after all, the higher the paper class, the more the number, get the more reward. So most of the university teachers like to do scientific research.

Most teachers are not interested in teaching, and even some teachers hope themselves without class, devoted to do scientific research. There are two main reasons: Firstly, Chinese university teachers class fees generally in the 20 or 30 yuan to 70 or 80 yuan, even if teachers do not do research, devoted to teaching, each semester class fees also not much money, class fees by hard teaching less than the research reward obtained by publishing several papers of high-grade each semester. Secondly, even better the teacher's class, higher student satisfaction with the teachers, and even students scoring full marks for the teachers, teachers' class fees will not be increased. So teachers aren't interested in teaching.

\section{Perspective of scientific research and teaching work in the university}

At present, the phenomenon of valuing scientific research above teaching work still exist in the teaching and research university of China, there are many unknown sides of scientific research and teaching in the university. The author reveal the biggest beneficiaries behind in this imbalance are teachers, the biggest victims are students via the perspective of scientific research and teaching.

\subsection{Perspective of scientific research in the university}

If university teacher do better research, not only helpful to professional evaluation, and schools have research reward. High title is not only helpful to post employment, wages and benefits, but also get the respect of his peers, teachers get satisfaction from psychological, is the so-called gain both fame and wealth. In particular, the national natural science fund budget a lot, even in the national youth fund has around 200000 yuan, plus schools 1:1 or 1:1.5 matching funds, added up to 500000 yuan or so.Country spend a lot of money on funds each year, and finance grows annually, the school encourage teachers to declare project actively every year. I interviewed a teacher of 211 universities who presiding the key project of national natural science fund and asked him :"you have such a large project, why you drive all day outside playing, can't see you do research in laboratory?" The teacher smiled and replied : "research in no hurry, buy a car for fun first, if not, how to spend more than 2 million yuan?" There exist some problems in university scientific research:

To begin with, whether the finance of provincial project or national natural science fund is too much or not? Whether when school finance department audit reimbursement of teachers' scientific research funds is not strict or not? Some of projects are basic, it is necessary to give so much money? Even if the above appropriation, teachers really put all the research fund to do research? The answer is obviously no!
Premier Li Keqiang presided over a State Council Executive meeting January 22,2014, decided to reform the Central Government research project and financial management approach. I hope that the relevant departments to put into practice the spirit of the meeting to manage the research funds.

Furthermore, now the university teachers under the pressure of professional evaluation, so the phenomena of trying various ways to publish papers, asking other people to write paper, buying paper, low level repeated research, making use of social relationship are produced in university, which is the academic corruption that we often talk about.Recently CCTV reported an alleged paper plagiarism event, the author is an academician of the Chinese Academy of Sciences, later the academician mentors jointly wrote to the Chinese Academy of Sciences, required to remove the academician. After I read this news, I felt ridiculous and hateful: so academicians can be false, now what else can not be faked? A great probability of China 211 or 985 colleges presiding Natural Science Foundation, most of presiders are master tutor or doctoral tutor, they engaging in these projects only themselves? The answer is obviously negative. Tutor recruit master or doctor every year, the project will be handed directly to the students, if Dr want to graduate, they must complete the task that their mentor give them. Some tutors directly add their name to paper that students have completed as the first author, students' work so mercilessly possessed by the tutor. Students can't get even a penny of scientific research funds, this is what we usually say the meaning of "free to work for the boss". This kind of phenomenon exists in almost all universities with master's or doctor's degree, isn't this academic corruption? Some university teachers have published more than a dozen or even dozens of papers each year, they spend so much time on writing papers, and still have focus on teaching? So many papers published every year, can guarantee the quality of the articles is very high? Teachers annually published dozens of papers in foreign countries, especially in the United States do not exist, are common in China, why have this strange phenomenon? Because schools have scientific research reward, so teachers will desperatedly publish papers for money, such low levels of repetitive research and low quality of classroom teaching are inevitable.

Thirdly, some university teachers wrote a lot of theoretical research papers, it is difficult to translate into productivity and to apply in practice, this is known as achievements transformation problem.Write so many articles, and can not be applied in practice, may I ask what is the use? I have interviewed many teachers, understand that some teachers have looked through papers, there are even the teacher smiled and said :"what is a paper? A paper is theoretical article,the more esoteric, the higher probability the paper can be published, if experts can not understand your paper, then it is sure to be issued. Believe that the Chinese teaching research university teachers have published many theoretical papers and cannot be applied in the actual production and life. Teachers spent so much time and energy 
to do scientific research and do not have practical value in the end, and the competent department give so many scientific research funds, isn't this thuggery? This phenomenon does not need to be reformed?

Fourthly, teachers declare provincial or national natural science fund project every year, only the recommended declarations by school have the chance to be reviewed, and some unjust phenomena exist in some schools. The draft declaration have to be reviewed by school expert committee, only passed the first review, are eligible to be recommended, results show that recommended mostly have a good relationship with leadership, unless you have strong scientific research strength, otherwise the possibility of being recommended is very small, this phenomenon still exist in some university, this is the corruption of power. Some school teachers even have no chance to write the first draft declaration, because the school recommended declaration quantity is limited, the school will distribute the total number to each branch department equally, the leadership of each branch recommend list of teachers' declaration, it would be much corruption.

Fifthly, journal of some well-known university basically published their teachers' papers, it is difficult to publish the papers for outside school teachers, it is scientific research monopoly corruption. EI journal list will be adjusted every year, often a well-known domestic journal was kicked out of EI directory. Because the university journal is basically open internally, not open to the public, unless the author's paper append a big project funds, such as the general,key or major projects of national natural science foundation of China, 985 project or torch project and so on. I read a lot of papers with large project fund, found some articles actually written generalized, some papers without fund written well.

\subsection{Perspective of teaching work in the university}

Firstly, many teachers will spend time and energy on the scientific research, so little time spent on teaching, class is able to accomplish the task of teaching, the teaching quality is not high, just don't be late for class, do not leave early, even in low students' grade of teacher will not affect the actual income of the teachers. On the contrary, if the teacher's lecture is better, spend more time and energy on teaching, students' score higher again, school also won't go to praise teachers, also won't lead to higher income return, so most teachers feel boring in class, teaching just to get by, caused a lot of school graduating class students not come to class ${ }^{[13]}$.

Secondly, some university teachers' professional level is limited. Such as the main courses "circuit" and "automatic control principle", some teachers in the teaching of "circuit" don't explain "Laplace transform" or "network function" or "circuit equations in matrix form" and other chapters. In the teaching of "automatic control principle", don't explain "the analysis and correction of linear discrete system" or "nonlinear control system analysis" or "the state space analysis and synthesis of linear systems" and so on. These contents are very difficult, and at the same time the scores in postgraduate entrance examination are considerable. The teachers in class do not explain the content, only on simple chapters' content, does not rule out the possibility of these teachers in these chapters may not skilled. It does not harm the younger generation?

Thirdly, part of the university teachers' mandarin is not up to the corresponding level, and some even stutter. Bad mandarin teachers in the classroom can make do with lectures, students just listen to the teacher unnaturally, but also can make do with understand, if stuttering teachers give students a lecture, the students will suffer. Schools are advised to keep this part of teachers transferred or dismissal, like the teacher you don't know how to speak in class should not harm students?

Fourthly, many schools hold excellent teaching quality award selection activities at the end of each semester, hold excellent teaching achievement award each year, finally winning is department head, the teachers have contributions in teaching truly, outstanding teaching performance but not winning, so many teachers see through teaching, isn't this corruption in teaching?

\section{Practical measures to solve the scientific research and teaching imbalance}

Aiming at the phenomenon of valuing scientific research above teaching work, I put forward some practical measures as follows.

Firstly, the competent departments in the allocation of research funding should consider difficult subjects, not onesize-fits-all. Such as pure basic research in mathematics, physics and other subjects, these subjects' theory is stronger, when project finished, just published a few articles, do not need to purchase the equipments, so can be reduced the allocation of research funding. Like basic applied research in electrical engineering disciplines, due to the purchase of scientific equipments, can be a little more allocation of research funding.

Secondly, the allocation of research funding from the custody of the provincial department of finance, not kept by the schools themselves, teachers' scientific funding can be reimbursed with official card, anhui province began to try to operate from 2014, other provinces can learn from it.

Thirdly, when project finished, not just look at how many papers were published. If it is a basic applied research project, to see whether the project have actual system debugging and practical application effect.

Fourthly, in the future the school ranked not only look at the scientific research strength, but also to consider the quality of teaching and students' scores, school research reward should not be too high, otherwise it will induce the teachers to value scientific research above teaching work.

Fifthly, when the teacher declared a provincial or national project, the draft declaration should be sent to the outside, reviewed by outside experts, not the school inside reviewed. 
Sixthly, editorial office of famous university journal should send the received manuscript to outside experts, and also blind trial, the so-called blind trial is to remove all the relevant information of author and fund project number.

Seventhly, school should not only improve class fee standard to the teachers of good teaching effect and high students' score, but also give additional material rewards. Simultaneously, school give priority to these teachers declaring excellent teaching achievement prizes.

Eighthly, the school in the recruitment of teachers should be the same as some foreign companies, implement examination system including mandarin test, more difficult knowledge questions be tested, so as to check the true level of teachers, preferred eventually.

Ninthly, school should hold examination and evaluation to teachers each semester, like hospital medical staff attending exam twice a year, university teachers should also participate in the school's exam, exam is a written examination and theory of experimental operation, unqualified teachers can be given the chance to make up, teachers not passed in makeup exam should be transfered or dismissal.

Tenthly, provincial education department in the future professional evaluation should not only look at teachers' scientific research achievements, should be classified processing, teachers good at teaching should be given teaching professor, teachers good at scientific research should be given research professor.

\section{Conclusion}

The main cultivate object are students in university, students learned knowledge, can contribute to the state after they step into the society. The phenomenon of valuing scientific research above teaching work in teaching and research university of China exist for a long time. If this kind of phenomenon can not be reformed as early as possible, and ultimately the largest benefit group are teachers, the largest victim group are students. If students will not lay a solid foundation, how to make contributions to the country when they go into society? If things go on like this, the nation is in peril. Therefore, the reform of scientific research and teaching imbalance is imperative.

\section{References}

[1] Li Baobin, Xu Xiaodong.Analysis and reflections on the imbalance between teachers' research and teaching abilities in university teachers' evaluation, Research in higher education of engineering, 2011, 2: 76-81.

[2] Xu Lihua, Fu Jinhui.The imbalanced reasons of teaching and scientific research in university, Heilongjiang researches on higher education, 2007, 10: 33-35.

[3] Zhang Hongbing.The imbalance of teaching and scientific research in Chinese university, Journal of chendu college of education, 2006, 20 (1): 33-34.

[4] Xie min, Liu Xiaobo.The reasons and strategies of imbalanced teaching and scientific research in Chinese university, China electric power education, 2009, 3: 10-11.

[5] Zhao Xinghua.The imbalance phenomenon of teaching and scientific research of Chinese university in recent years, Journal of yanshan university (philosophy and social science edition), 2009, 10 (2): 132-133.

[6] Liu Zhenshen.The imbalance and coordination of teaching and scientific research in colleges and universities, Science and technology information, 2012, 35: 782-784.

[7] Gao Yongqin, Hao Haisen.The strategies study of imbalanced teaching and scientific research in Chinese university, China economic and trade herald, 2009, 23: 99.

[8] Li Tian, Wang Zhuojun.The reasons and strategies study of imbalanced teaching and scientific research in higher education, The science education article cultures, 2010, 12: 27-28.

[9] Zhou Nan.The negative impact of the imbalance on university teachers' scientific research and teaching evaluation in teacher morality construction, The science education article cultures, 2008, 7: 10 .

[10]Zhao Zhenjun.Valuing scientific research above teaching work is a false proposition, Higher education exploration, 2006, 2: 21-23.

[11]Nan Jiandang.Economic analysis of valuing scientific research above teaching work in university,Statistics and decision, 2007, 20: 67-69.

[12] Xu Jun.Imbalance causes and coordinated measures of Chinese college teaching scientific research, Modern distance education, 2009, 6: 36-39.

[13]Zhao Haibo.The survey and research of "empty nest phenomenon"in college graduating class, China electric power education, 2010, 6: 186-18. 